STUDI

FRANCESI

\section{Studi Francesi}

Rivista quadrimestrale fondata da Franco Simone

165 (LV | III) | 2011

LA RAPPRESENTAZIONE DELLA MADRE NELLA

LETTERATURA FRANCESE DEL NOVECENTO a cura di Dario Cecchetti e Michele Mastroianni

\title{
Midori Ogawa, Voix, musique, altérité. Duras, Quignard, Butor
}

\section{Stefano Genetti}

\section{(2) OpenEdition \\ Journals}

Edizione digitale

URL: http://journals.openedition.org/studifrancesi/5146

DOI: 10.4000/studifrancesi.5146

ISSN: 2421-5856

Editore

Rosenberg \& Sellier

Edizione cartacea

Data di pubblicazione: 1 décembre 2011

Paginazione: 678-679

ISSN: 0039-2944

Notizia bibliografica digitale

Stefano Genetti, «Midori Ogawa, Voix, musique, altérité. Duras, Quignard, Butor», Studi Francesi [Online], 165 (LV | III) | 2011, online dal 30 novembre 2015, consultato il 13 janvier 2021. URL: http://

journals.openedition.org/studifrancesi/5146 ; DOI: https://doi.org/10.4000/studifrancesi.5146

Questo documento è stato generato automaticamente il 13 janvier 2021.

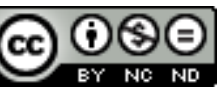

Studi Francesi è distribuita con Licenza Creative Commons Attribuzione - Non commerciale - Non opere derivate 4.0 Internazionale. 


\title{
Midori Ogawa, Voix, musique, altérité. Duras, Quignard, Butor
}

\author{
Stefano Genetti
}

\section{NOTIZIA}

MIDORI OGAWA, Voix, musique, altérité. Duras, Quignard, Butor, Paris, L'Harmattan, 2010

(«Trait d'union»), pp. 208.

1 I saggi che compongono questa coesa e convincente raccolta sono distribuiti in tre parti, incentrate rispettivamente sulle questioni della voce in quanto ambigua origine della scrittura, del corpo e della resistenza che esso oppone alla parola e, infine, della musica. Il dialogo tra le arti è qui inteso come stimolo a esplorare i limiti del letterario. Mediata dal fallimento dell'incarnazione pittorica in Le Chef-d'œuvre inconnu di Balzac, dal commento di Bataille all'Olympia di Manet e dalle considerazioni di Didi-Huberman sull'inestricabilità di sguardo e visione, è ad esempio una riflessione sulla tensione tra il nudo portatore di significati ideali e la nudità esibita come eccesso e assenza di senso, che travalica il visibile e il dicibile, a guidare - in «Une Ève marine que la lumière devait enlaidir» (Marguerite Duras) (pp.91-111) - l'analisi dei ritratti di Anne-Marie Stretter e dell'anonima donna di La Maladie de la mort: reticenti e instabili, essi fanno del corpo un (s)oggetto del desiderio che veicola un turbamento del vedere. Dei rapporti tra letteratura e musica che attraversano la narrativa del Novecento da Proust a Gailly, l'autrice si è recentemente occupata anche a proposito dei Grands moments d'un chanteur di Louis-René des Forêts nel numero di «Recherches et Travaux» $(77,2010)$ curato da Claude coste e Betrand VIBERT e il cui titolo, La Haine de la musique, è mutuato da Quignard (si veda anche Timothée PICARD, La Littérature contemporaine a-t-elle retrouvé un modèle musical?, nel numero dedicato a Quignard di «Europe», 976-977, agostosettembre 2010, pp.52-76). Modello compositivo ed espressivo sfuggente, la musica diventa oggetto di un confronto a distanza, differito e interiorizzato, come in Dialogue avec 33 variations de Ludwig van Beethoven sur une valse de Diabelli di Butor, dove l'iperdeterminazione dell'ascolto si fa interazione poietica secondo un «processus 
créateur en miroir et en abyme» (p. 139) esaminato in Dialogue/Dialogue, Butor/Beethoven (pp. 135-170).

2 Due articoli hanno per oggetto la scrittura di Quignard: scrittura silenziosa che ubbidisce a una voce perduta, inscritta appunto in quanto irrecuperabile (Hypothèses de la voix, pp. 61-88), e scrittura frammentaria, ipocondriaca, che in Les Tablettes de buis d'Apronenia Avitia, Albucius o La Raison trasforma il romanzo in un reliquiario dove trovano spazio le membra, le secrezioni e gli effluvi di un corpo franto, riflessi e relitti della pars obscena che rinviano alla scena sessuale da cui proveniamo come a una scena invisibile, a una irrimediabile mancanza (De l'érotisme à la mélancolie: les exemples romains, pp.113-131, inedito). Le rimanenti letture riguardano l'opera di M. Duras. Si tratta di La Voix en souffrance ou 'internal difference' (pp. 25-42) - sulle due voci fuori campo che fanno di La Femme du Gange «une vaste chambre d'échos» (p. 12), ma anche su Moderato cantabile, L'Amant, Emily L. - e di La Voix (dés)incarnée (pp. 43-60), sull'ecografia (p.57) del desiderio, tanto immediato quanto indeterminato, dettato dall'intrecciarsi di voci fantasmatiche, senza viso né corpo, in Le Navire Night. Nell'inedito Variations sur un nom oublié. La musique dans le 'cycle indien' (pp. 171-198), infine, l'A. mostra come l'impianto di Le Ravissement de Lol V. Stein, Le Vice-Consul e India Song-(de)costruzione dei personaggi, riconfigurazione del tempo ed erosione del romanesque - rispondano a dislocazioni e slittamenti di senso caratteristici della frase musicale, nel contesto di una scrittura che rimanda «à son propre geste» (p. 197) riarticolando incessantemente memoria e oblio, iterazione e variazione. 